\title{
Simultaneous determination of paracetamol and diphenhydramine hydrochloride mixture in the presence of their degradation products
}

\author{
NouruddinW. Ali ${ }^{1}$, M. Abdelkawy ${ }^{2}$ and Nessreen S. Abdelhamid ${ }^{3}$

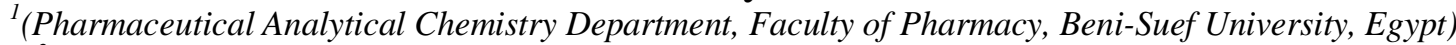 \\ ${ }^{2}$ (Pharmaceutical Analytical Chemistry Department, Faculty of Pharmacy, Cairo University, Egypt) \\ ${ }_{3}^{3}$ (Pharmaceutical Analytical Chemistry Department, Faculty of Pharmacy, Beni-Suef University, Egypt)
}

\begin{abstract}
New accurate, selective, sensitive and precise methods were developed and validated for determination of paracetamol and diphenhydramine hydrochloride in the presence of P-amino phenol, the hydrolytic degradate and the most potential impurity of paracetamol and the $N$ oxide degradation product of diphenhydramine in bulk form and in pharmaceutical formulation.Method A uses double divisor second derivative of ratio spectrophotometric technique, at $304 \mathrm{~nm}$ for paracetamol and $256.4 \mathrm{~nm}$ for diphenhydramine hydrochloride. Method B utilizes Principle Component Regression (PCR) and Partial Least Squares (PLS) chemometric techniques for quantification of the four components using a UV spectrum range of 210-350 nm. The proposed methods were successfully applied to the analysis of the mentioned drugs either in bulk powder or in pharmaceutical formulation without interference from other dosage form additives, and the results were statistically compared with the pharmacopoeial method.
\end{abstract}

Keywords:Paracetamol, diphenhydramine hydrochloride, P-amino phenol, double divisor spectrophotometric method, multivariate spectral analysis.

\section{Introduction}

Paracetamol (PC) is N-(4-hydroxy phenyl) acetamide. It is Para- aminophenol derivative; it has analgesic and anti-pyretic properties [1].Diphenhydramine hydrochloride (DH) is 2-Diphenyl methoxy$\mathrm{N}$, Ndimethylethanamine, it has antihistaminic action and used for symptomatic relief of hypersensitivity reactions [2].Their structures are shown in "Fig.1".
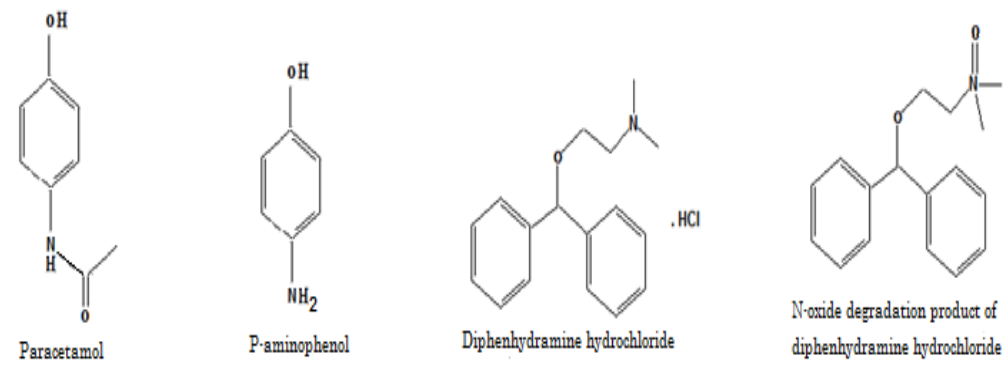

figure 1.structures of the studied drugs.

PC and DH are co-formulated in Panadol night tablets for temporary relief of pain associated with sleeping disorders. Simultaneous determination of the two drugs is time saving and less tedious than the determination of the two drugs by separate methods. The U.S. Pharmacopeia (USP 2007) has described a monograph to determine the binary mixture of PC and DH, depending on RP-HPLC using $\mathrm{C}_{18}$ column and phosphate buffer- acetonitrile in the ratio of $94: 6 \mathrm{v} / \mathrm{v}$ as a mobile phase with UV detection at $225 \mathrm{~nm}$ [3].

Few analytical methods have been described for simultaneous determination of PC/DH binary mixture including HPLC methods [4-6], NIR spectroscopy [7] and multivariate spectrophotometry [8]. A single published literature described the simultaneous quantification of PC and DH in presence of P-amino phenol (PAP); by first derivative $\left({ }^{1} \mathrm{D}\right)$ spectrophotometric, the first derivative of ratio spectra $\left({ }^{1} \mathrm{DD}\right)$, multivariate spectrophotometric and HPTLC-densitometric methods, in bulk material and pharmaceutical preparations [9].

Therefore the aim of this work is to describe a simple, sensitive, precise, accurate and time saving method for the simultaneous determination of $\mathrm{PC}$ and $\mathrm{DH}$ in the presence of both PAP and the $\mathrm{N}$ oxide 
degradation product of DH, Diphenylmethoxy-N,N-dimethyl ethanamine N-oxide (NOD), which can be used in pure forms or in pharmaceutical formulation.

\section{Experimental}

\subsection{Materials}

\subsubsection{Pure standards.}

Paracetamol and Diphenhydramine Hydrochloride were kindly supplied by GlaxoSmithKline Company Egypt. Their purity was found to be $100.11 \pm 1.197 \%$ and $99.96 \pm 0.743 \%$, respectively according to the official HPLC method [3].

\subsubsection{Pharmaceutical formulation.}

Panadol night ${ }^{\circledR}$ tablets (Batch No. 124992) labeled to contain $500 \mathrm{mg}$ of Paracetamol and $25 \mathrm{mg}$ of Diphenhydramine Hydrochloride, manufactured by GlaxoSmithKline company .

2.1.3. Chemicals and reagents.

All reagents and chemicals used throughout this work were of analytical grade and were used without further purification. Methanol was of HPLC grade and obtained from ChromasolvW, Sigma-Aldrich ChemieGmbh,Germany. Ethyl acetate was from E. Merck, Germany, Hydrogen peroxide solution, sodium lauryl sulphate and acetone and acetic acid were from Al-Nasr pharmaceutical chemicals company, Abu Zaabal, Cairo, Egypt. P-aminophenol was from Riedel-dehaen-AG- Germany; its purity was certified to be $99 \%$.

2.1.4. Preparationof $\mathrm{N}$ oxide degradation product (NOD).

A $0.2 \mathrm{~g}$ aliquot of $\mathrm{DH}$ powder was mixed with $5 \mathrm{~mL}$ of $1 \mathrm{M}$ sodium hydroxide solution to liberate the free base which was then extracted by ether followed by spontaneous vaporization of the solvent. $5 \mathrm{~mL}$ of $30 \%$ hydrogen peroxide solution is added to the free base and covered carefully. Six hours were sufficient for complete oxidation of the free base. The reaction progress was followed via TLC using ethyl acetate - acetone methanol - acetic acid - sodium lauryl sulphate (5:5:1:0.25:0.2, v/v/v/v/w)as a developing system. After complete oxidation, the solution was left to dry at room temperature and the degradation product powder was identified by IR and mass spectrometry, and used for preparation of the stock solution of the degradation product.

\subsection{Instruments}

A UV lamp with short wavelength $254 \mathrm{~nm}$ (USA) and a double beam UV-visible spectrophotometer (SHIMADZU, Japan) model UV-1601 PC with quartz cells of $1 \mathrm{~cm}$ path length, connected to IBM compatible computer. The software was UVPC personal spectroscopy software version 3.7. Data analysis was performed using PLS-Toolbox 2.0 running under MATLAB, version 6.5.

\subsection{Prepared solutions}

2.3.1. StandardsolutionsFor stock standard solutions of PC, DH, PAP and NOD ( $1 \mathrm{mgmL}^{-1}$ in methanol), $0.1 \mathrm{~g}$ of each of the four components were accurately weighed into four separate $100 \mathrm{~mL}$ volumetric flasks; $50 \mathrm{~mL}$ of methanol was added to each flask and shaken to dissolve, then the volume was made up to the mark with methanol. For working standard solutions of PC, DH, PAP and NOD $\left(100 \mu \mathrm{gmL}^{-1}\right), 10 \mathrm{~mL}$ of each stock standard solutions $\left(1 \mathrm{mgmL}^{-1}\right)$ were transferred accurately into four separate $100 \mathrm{~mL}$ volumetric flasks, and then the volume was completed to the mark with methanol.

\subsubsection{Laboratory prepared mixtures}

Mixtures containing different ratios of PC, DH, PAP and NOD were prepared using their respective working solutions in methanol.

\subsection{Methodology}

2.4.1. Double divisor second derivative of ratio ${ }^{2} \mathrm{DD}$ spectrophotometric method

2.4.1.1. Linearity and construction of calibration curves

The ${ }^{2} \mathrm{DD}$ spectra of $\mathrm{PC}$ and $\mathrm{DH}$ in a concentration range of $2-45 \mu \mathrm{gmL}^{-1}$ for each drug were recorded using a mixture of PAP and NOD containing $10 \mu \mathrm{gmL}^{-1}$ of each as a divisor, $\Delta \lambda=8$ and scaling factor $=500$. The peak amplitudes were measured at $304 \mathrm{~nm}$ for PC and at $256.4 \mathrm{~nm}$ for DH.

The calibration curves were constructed relating the peak amplitudes to the corresponding concentrations for each drug. The regression equations were computed.

2.4.1.2. Analysis of laboratory prepared mixtures of PC, DH, PAP and NOD

Mixtures containing different concentrations of PC, DH, PAP and NOD were analyzed by applying the abovedescribed procedure"Table 1".

2.4.2. Chemometric methods 


\subsubsection{Construction of the training set}

Five level four factor calibration design was used [10]. Different mixtures containing different ratios of PC, DH, PAP and NOD were prepared "Table 2, mixtures 1-13".

The absorption spectra of the mixtures were recorded and transferred to MATLAB for data manipulation. Thirteen mixtures were used to construct the calibration model and twelve mixtures were used as a validation set. PCR and PLS multivariate calibration models were constructed and were found to have high spectral residuals in the regions below $210 \mathrm{~nm}$ and above $350 \mathrm{~nm}$; so these regions were rejected.

For the selection of the optimum number of factors; the cross validation method was used leaving one sample out at each time, then predicting its concentration. The root mean square error of validation was calculated by comparing the predicted and the actual concentrations of each drug in the thirteen calibration mixtures. Data mean centering gave better results upon building PCR and PLS models.

2.4.2.2. Construction of the validation set

Twelve different mixtures containing different ratios of PC, DH, PAP and NOD were prepared and used as a validation set (table 2, mixtures14-25); where the concentrations of all components were predicted using the developed models.

Table 1. Determination of paracetamol (PC) and diphenhydramine hydrochloride (DH) in presence of $\mathrm{P}$ aminophenol (PAP)and the N-oxide degradation product of diphenhydramine (NOD) in laboratory prepared mixtures by the double divisor ${ }^{2} \mathrm{DD}$ method.

\begin{tabular}{|c|c|c|c|c|c|c|}
\hline \multirow[b]{2}{*}{$\begin{array}{c}\text { Mixture } \\
\text { No. }\end{array}$} & \multirow[b]{2}{*}{$\begin{array}{l}\text { Ratio of } \\
\text { PC:DH }\end{array}$} & \multirow[b]{2}{*}{ Degradation products $\%$} & \multicolumn{2}{|c|}{ PC } & \multicolumn{2}{|c|}{ DH } \\
\hline & & & $\begin{array}{l}\text { Taken } \\
\left(\mu \mathrm{gmL}^{-1}\right)\end{array}$ & $\begin{array}{c}\text { Recovery } \\
\text { (\%) }\end{array}$ & $\begin{array}{c}\text { Taken } \\
\left(\mu \mathrm{gmL}^{-1}\right)\end{array}$ & $\begin{array}{c}\text { Recovery } \\
(\%)\end{array}$ \\
\hline 1 & $1: 1$ & $10 \%$ & 36 & 99.583 & 36 & 99.417 \\
\hline 2 & $2: 1$ & $20 \%$ & 32 & 100.969 & 16 & 101.563 \\
\hline 3 & $1: 2$ & $30 \%$ & 7 & 100.857 & 14 & 100.357 \\
\hline 4 & $5: 1$ & $40 \%$ & 15 & 99.733 & 3 & 99.333 \\
\hline 5 & 10:1 & $50 \%$ & 20 & 99.750 & 2 & 99.500 \\
\hline 6 & $20: 1$ & $60 \%$ & 40 & 101.300 & 2 & 99.000 \\
\hline 7 & 20:1 & $70 \%$ & 40 & 99.650 & 2 & 101.500 \\
\hline 8 & 20:1 & $80 \%$ & 40 & 100.900 & 2 & 100.500 \\
\hline 9 & $20: 1$ & $90 \%$ & 40 & 99.325 & 2 & 101.000 \\
\hline \multicolumn{3}{|c|}{ Mean \pm SD } & & $\begin{array}{c}100.230 \\
\pm \\
0.757\end{array}$ & & $\begin{array}{c}100.241 \\
\pm \\
0.973 \\
\end{array}$ \\
\hline
\end{tabular}

Table 2. Mixtures of paracetamol (PC), diphenehydramine hydrochloride (DH), P-aminophenol (PAP) and N oxide degradation product of diphenehydramine (NOD) used in training and validation sets.

\begin{tabular}{|c|c|c|c|c|}
\hline \multirow{2}{*}{ Mixture no. } & \multicolumn{4}{|c|}{ Concentrations in $\mu \mathrm{g} \mathrm{mL}^{-1}$} \\
\hline & PC & DH & PAP & NOD \\
\hline 1 & 20 & 9 & 9 & 7 \\
\hline 2 & 25 & 15 & 9 & 9 \\
\hline 3 & 30 & 12 & 15 & 7 \\
\hline 4 & 25 & 9 & 15 & 11 \\
\hline 5 & 20 & 15 & 3 & 11 \\
\hline 6 & 30 & 15 & 12 & 3 \\
\hline 7 & 30 & 3 & 3 & 9 \\
\hline 8 & 10 & 12 & 9 & 3 \\
\hline 9 & 25 & 3 & 12 & 7 \\
\hline 10 & 10 & 9 & 12 & 9 \\
\hline 11 & 20 & 12 & 6 & 9 \\
\hline 12 & 25 & 12 & 3 & 5 \\
\hline 13 & 25 & 6 & 6 & 3 \\
\hline 14 & 15 & 3 & 9 & 5 \\
\hline 15 & 10 & 6 & 3 & 7 \\
\hline 16 & 15 & 9 & 3 & 3 \\
\hline 17 & 20 & 3 & 15 & 3 \\
\hline 18 & 10 & 3 & 6 & 11 \\
\hline 19 & 10 & 15 & 15 & 5 \\
\hline 20 & 30 & 6 & 9 & 11 \\
\hline 21 & 15 & 15 & 3 & 7 \\
\hline 22 & 30 & 9 & 3 & 5 \\
\hline 23 & 20 & 6 & 12 & 5 \\
\hline 24 & 15 & 6 & 15 & 9 \\
\hline 25 & 15 & 12 & 12 & 11 \\
\hline
\end{tabular}

\subsubsection{Application to pharmaceutical formulation;Panadol night ${ }^{\circledR}$ tablets}

The contents of 10 Panadol night ${ }^{\circledR}$ tablets were powdered and mixed well. An accurately weighed portion of the powdered tablet equivalent to $100 \mathrm{mg}$ of $\mathrm{PC}$ and $5 \mathrm{mg}$ of DH was transferred into $100-\mathrm{mL}$ 
volumetric flask; $75 \mathrm{~mL}$ methanol was added and sonicated for $30 \mathrm{~min}$, completed to volume with methanol, and then filtered. Part of the above solution is diluted to obtain working solution of the dosage form containing $100 \mu \mathrm{gmL}^{-1}$ of $\mathrm{PC}$ and $5 \mu \mathrm{gmL}^{-1}$ of $\mathrm{DH}$. Applying the same procedure under double divisor ${ }^{2} \mathrm{DD}$ and multivariate spectral techniques, the concentrations of $\mathrm{PC}$ and $\mathrm{DH}$ were in the tablets were calculated from the computed regression equations.

\section{Results and discussion}

The main task of this work was to establish new simple, sensitive and accurate analytical methods for the simultaneous determination of PC and DH in presence of their degradates PAP and NOD in bulk powders and pharmaceutical dosage form with satisfactory precision for good analytical practice.

Upon adding $1 \mathrm{M} \mathrm{NaOH}$ to $\mathrm{DH}$, the free base was liberated from the hydrochloride salt of $\mathrm{DH}$. When $30 \%$ hydrogen peroxide solution is added to the free base and left for Six hours, complete oxidation took place into the N-oxide form (NOD) as shown in "Fig.2".

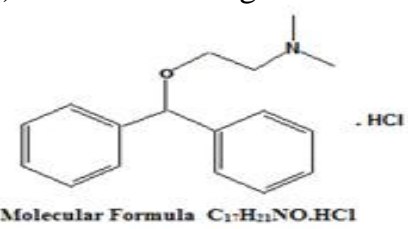

(Diphenehydramine hydrochloride)

Mol Wt 291
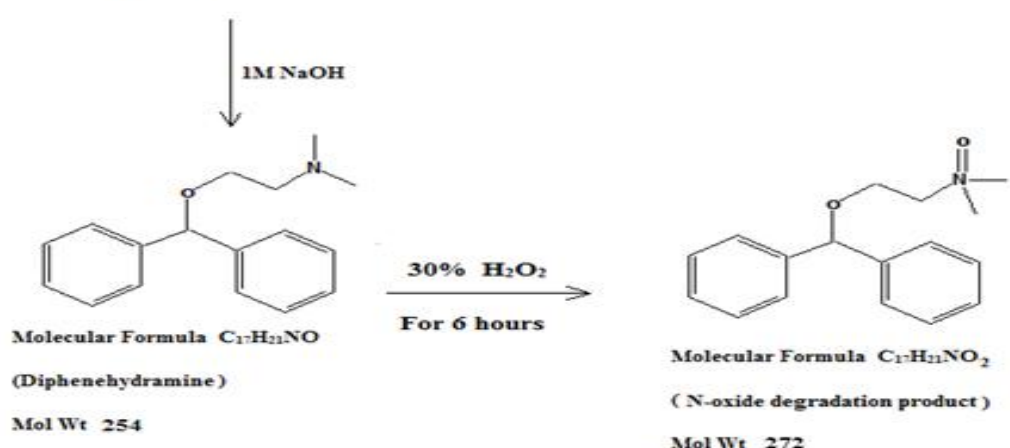

Mol We 272

figure 2.scheme of oxidative degradation of diphenhydramine hydrochloride.

The solution was evaporated at room temperature and the degradation product (NOD) was identified by IR and mass spectrometry, where the appearance of a strong band corresponding to the $\mathrm{N}$-oxide group at $1550 / \mathrm{cm}$ in the IR spectrum of NOD which is almost absent in the IR spectrum of DH is an evidence of the oxidation to the N-oxide form of the drug under the stated conditions as shown in "Fig.3".

The mass spectra of DH and NOD also confirmed their identity as mass molecular ion peaks at $\mathrm{m} / \mathrm{z} 290$ and 272 corresponded to the intact drug (DH) and its degradation product (NOD), respectively, as shown in "Fig.4".

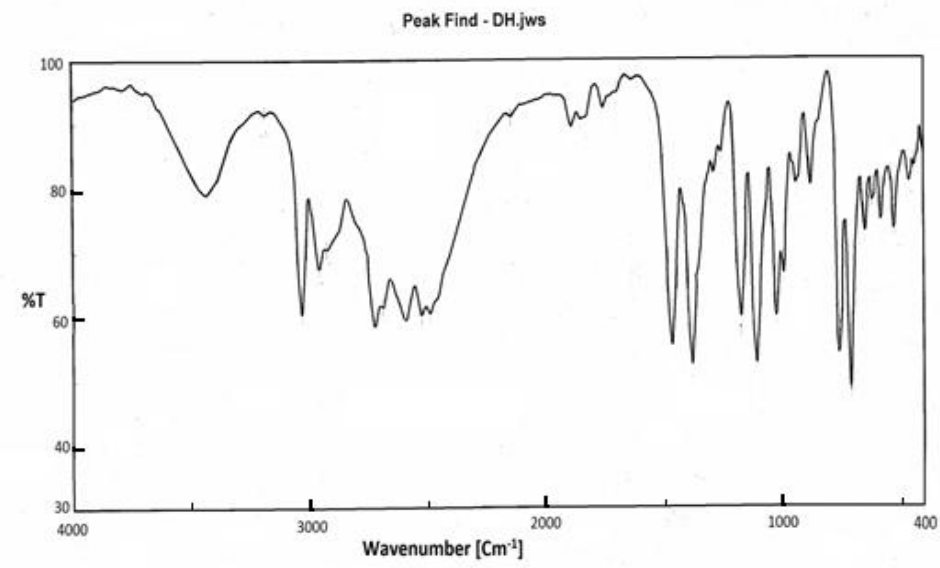


(a)

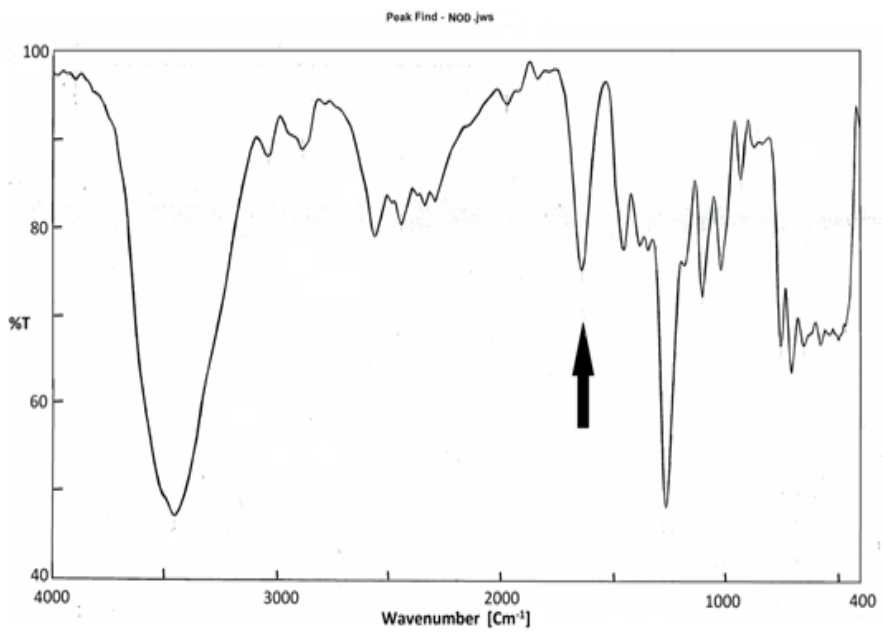

(b)

figure 3.infrared spectra of diphenhydramine hydrochloride (a) and its $\mathrm{N}$-oxide degradation product Diphenylmethoxy -N,Ndimethylethanamine N-oxide (b).

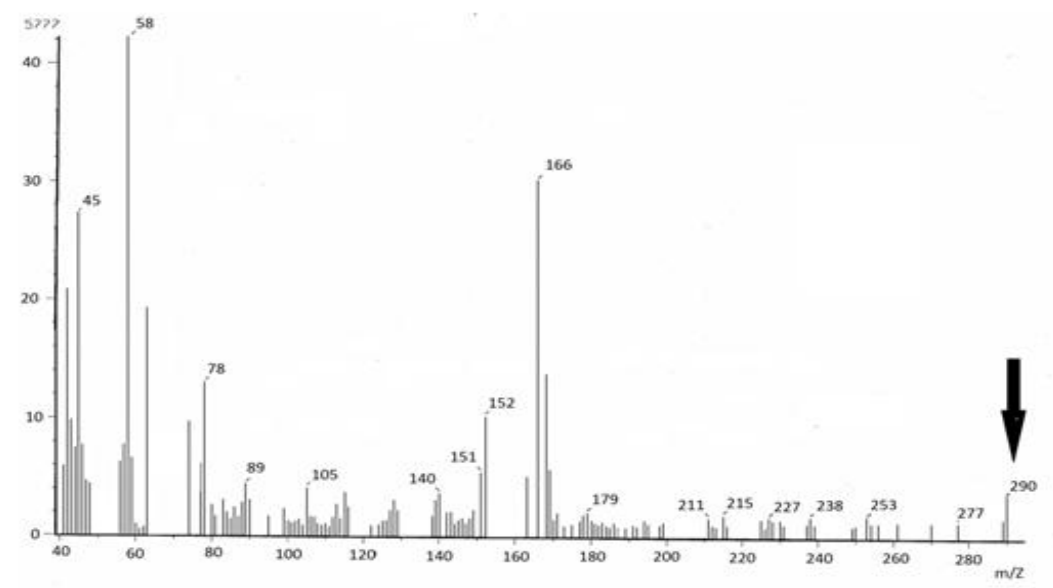

(a)

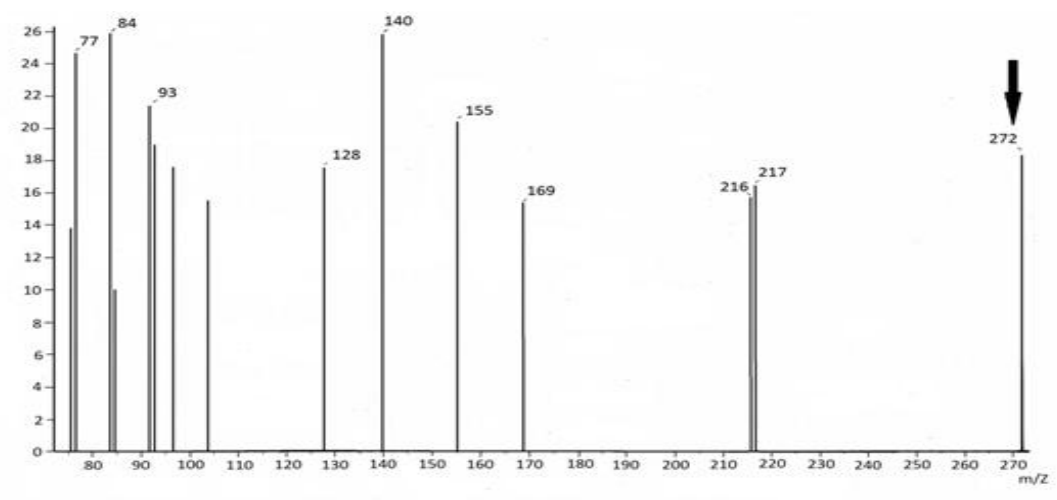

(b)

figure 4.mass spectra of diphenhydramine hydrochloride(a) and its $\mathrm{N}$-oxide degradation product Diphenylmethoxy-N,N-dimethyl ethanamine N-oxide(b). 


\subsection{Double divisor ${ }^{2} \mathrm{DD}$ spectral method}

The double divisor derivative ratio spectral method depends on the use of coincident spectra of the derivative of the ratio spectra obtained by using a double divisor consisting of a sum of the spectra of two different components and measuring the amplitude at the maximum or the minimum wavelength.

The zero order absorption spectra of PC, DH, PAP and NOD show strong overlapping which prevents the direct spectrophotometric assay of PC or DH as shown in "Fig.5".

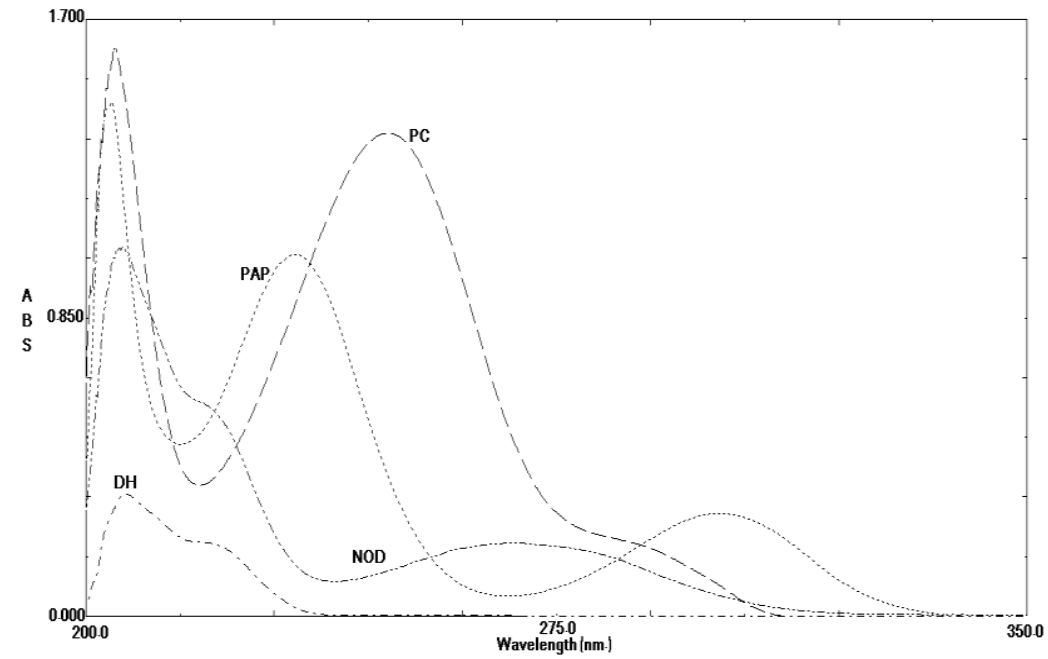

figure 5.the UV absorption spectra of paracetamol (- - - ), diphenhydramine hydrochloride (.....), paminophenol (..........) and $\mathrm{N}$ oxide degradation product of diphenhydramine hydrochloride (............).

The double divisor derivative ratio technique was applied to solve this problem for selective determination of each of PC and DH in presence of the two degradates PAP and NOD.

Selection of the divisor: differentconcentrations of PAP and NOD mixtures were tried as divisors. The best results in terms of sensitivity, selectivity and signal to noise ratio were obtained upon using a mixture of PAP/NOD $\left(10 \mu \mathrm{gmL}^{-1}\right.$ of each) as a divisor for determination of both PC and DH.

The absorption spectra were divided by the spectrum of a mixture of PAP/NOD $\left(10 \mu \mathrm{gmL}^{-1}\right.$ of each) used as a divisor and $^{2} \mathrm{DD}$ spectra were obtained were PC could be determined at $304 \mathrm{~nm}$ (a zero crossing point for $\mathrm{DH}$ ) and DH could be determined at $256.4 \mathrm{~nm}$ (a zero crossing point for PC) as shown in "Fig.6".

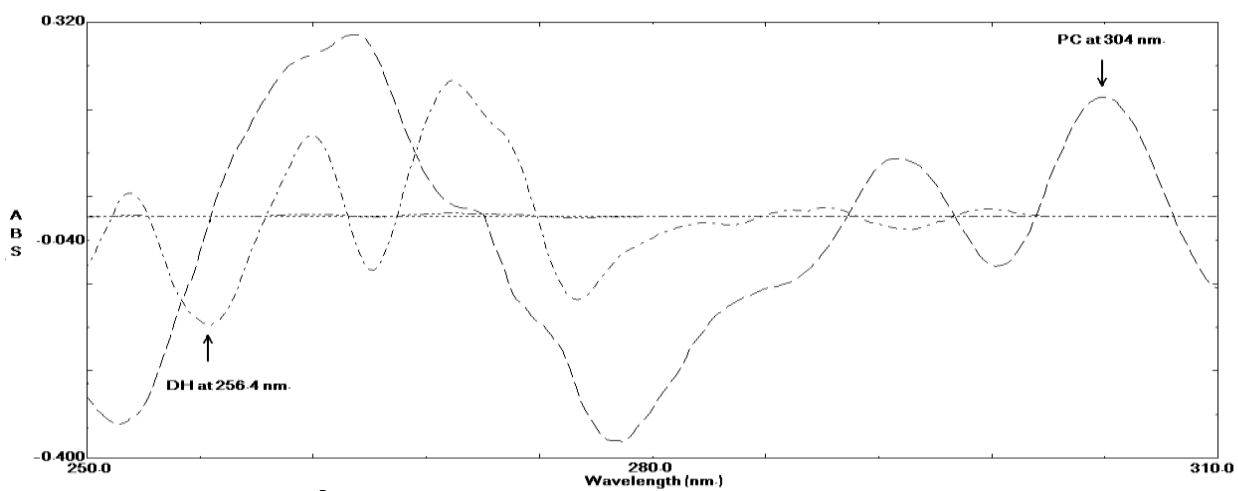

figure 6.the double divisor ${ }^{2} \mathrm{DD}$ spectra of paracetamol (- - -), diphenhydramine hydrochloride (.....), paminophenol (.........) and $\mathrm{N}$ oxide degradation product of diphenhydramine hydrochloride (...........), using a mixture of $10 \mu \mathrm{g} \mathrm{mL}{ }^{-1}$ of each of PAP and NOD as a divisor.

Linear correlations were found between concentrations of drugs and peak amplitudes at $304 \mathrm{~nm}$ for PC and at $256.4 \mathrm{~nm}$ forDH in the concentration range of $\left(2-45 \mu \mathrm{gmL}^{-1}\right)$ for both drugs. The regression equations were calculated and found to be:
$" Y_{1}=0.0392 C_{1}+0.0021(1)$
$" Y_{2}=0.0180 C_{2}+0.0038(2)$
$r_{1}=0.9999 \quad$ for $P C$ and
$r_{2}=0.9999$ for $\mathrm{DH}$

where $Y_{1}$ and $Y_{2}$ are the peak amplitudes at 304 and $256.4 \mathrm{~nm}, C_{1}$ and $C_{2}$ are the concentrations in $\mu \mathrm{gmL}^{-1}$, and $\mathrm{r}_{1}$ and $\mathrm{r}_{2}$ are the correlation coefficients for PC and DH, respectively. 
Good linearity is evident from the high values of the correlation coefficients and low values of intercepts, "Table 3".

The precision of the method was evident, as shown in "Table 3". The methods accuracy was checked by applying the methods for determination of pure samples of the studied compounds. The concentrations were calculated from the corresponding regression equations and good recoveries are shown in "Table 3".

Table 3. Results of assay validation parameters of the proposed double divisor ${ }^{2} \mathrm{DD}$ method for determination of paracetamol (PC) and diphenhydramine hydrochloride (DH) in presence of P-aminophenol (PAP) and the Noxide degradation product of diphenhydramine (NOD).

\begin{tabular}{|c|c|c|}
\hline Parameter & PC & DH \\
\hline Range $\left(\mu g m L^{-1}\right)$ & $2-45$ & $2-45$ \\
\hline \multicolumn{3}{|l|}{ Linearity } \\
\hline Slope & 0.0393 & 0.0180 \\
\hline Intercept & 0.0021 & 0.0038 \\
\hline Correlation coefficient & 0.9999 & 0.9999 \\
\hline Accuracy $($ mean \pm SD) & $100.526 \pm 0.773$ & $100.103 \pm 0.545$ \\
\hline \multicolumn{3}{|l|}{ Precision (RSD\%) } \\
\hline Repeatability $^{\text {a }}$ & 0.235 & 0.264 \\
\hline Intermediate precision $^{b}$ & 0.275 & 0.436 \\
\hline
\end{tabular}

Accuracy was further assessed by applying the standard addition technique on Panadol $®$ tablets, for which good recoveries were obtained, revealing no interference from excipients, and good accuracy of the methods "Table 4".

Table 4.Determination of paracetamol (PC) and diphenhydramine hydrochloride (DH) in Panadol night ${ }^{\circledR}$ tablets (batch no. 124992) by the proposed double divisor ${ }^{2} \mathrm{DD}$ method and multivariate techniques and application of standard addition technique.

\begin{tabular}{|c|c|c|c|c|c|c|}
\hline \multirow[b]{2}{*}{$\begin{array}{l}\text { Components } \\
\text { Taken } \\
\text { gmL }^{-1}\end{array}$} & \multicolumn{2}{|c|}{ 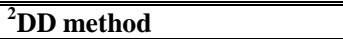 } & \multicolumn{2}{|l|}{ PLS } & \multicolumn{2}{|l|}{ PCR } \\
\hline & $\begin{array}{l}\text { Found } \\
(\% \pm \text { SD })\end{array}$ & $\begin{array}{l}\text { Standard } \\
\text { addition } \\
\text { mean } \pm \text { SD } \\
\end{array}$ & $\begin{array}{l}\text { Found } \\
(\% \pm \mathrm{SD})\end{array}$ & \begin{tabular}{|l} 
Standard \\
addition \\
mean \pm SD \\
\end{tabular} & $\begin{array}{l}\text { Found } \\
(\% \pm \text { SD })\end{array}$ & $\begin{array}{l}\text { Standard } \\
\text { addition } \\
\text { mean } \pm \text { SD } \\
\end{array}$ \\
\hline $\begin{array}{l}\mathbf{P C} \\
40\end{array}$ & $\begin{array}{l}98.360 \\
\pm 0.046\end{array}$ & $\begin{array}{l}100.250 \\
\pm 1.090\end{array}$ & $\begin{array}{l}98.300 \\
\pm 0.067\end{array}$ & $\begin{array}{l}100.057 \\
\pm 1.875\end{array}$ & $\begin{array}{l}98.320 \\
\pm 0.067\end{array}$ & $\begin{array}{l}100.833 \\
\pm 1.258\end{array}$ \\
\hline $\begin{array}{l}\text { DH } \\
2\end{array}$ & $\begin{array}{l}103.840 \\
\pm 0.380\end{array}$ & $\begin{array}{l}100.307 \\
\pm 0.992\end{array}$ & $\begin{array}{l}103.750 \\
\pm 0.431\end{array}$ & $\begin{array}{l}100.557 \\
\pm 0.916\end{array}$ & $\begin{array}{l}103.81 \\
\pm 0.468\end{array}$ & $\begin{array}{l}100.307 \\
\pm 1.481\end{array}$ \\
\hline
\end{tabular}

Selectivity of the proposed method is evident from the ${ }^{2} \mathrm{DD}$ spectra in "Fig. 6".Also, the method was applied for determination of PC and DH in laboratory-prepared mixtures as shown in "Table 1".

\subsection{Chemometric method:}

Different chemometric techniques were used for the simultaneous determination of PC, DH, PAP and NOD including PLS and PCR. The first step of the determination is the construction of the calibration set which consists of 13 mixtures containing different ratios of PC, DH, PAP and NOD, as shown in "Table.2, mixtures 113 ". The best results were obtained upon using the wavelength range of $210-350 \mathrm{~nm}$.

A validation set including 12 mixtures was used to validate the predictability of the models, where good results wereobtained“Table 2, mixtures 14-25".

Predicted concentrations were plotted against actual concentrations todetermine if the models accounted for the variation in the concentrations in the validation set.

The root mean square error of prediction [RMSEP] is a diagnostic tool which examines the errors in predicted concentrations, it indicates both precision and accuracy[10]. Model validation parameters are shown in "Table 5". 
Simultaneous determination of paracetamol and diphenhydramine hydrochloride mixture in the

Table 5.Results of assay validation parameters of the proposed multivariate methods for the determination of paracetamol (PC) and diphenhydramine hydrochloride (DH) in presence of P-aminophenol (PAP) and the Noxide degradation product of diphenhydramine (NOD).

\begin{tabular}{|l|l|l|l|l|l|l|l|l|l|}
\hline \multirow{2}{*}{ Validation parameters } & \multicolumn{2}{|l|}{ PLS } & \multicolumn{1}{l|}{ PCR } \\
\cline { 2 - 9 } & PC & DH & PAP & NOD & PC & DH & PAP & NOD \\
\hline Mean \pm SD & $\begin{array}{l}100.047 \\
\pm 1.357\end{array}$ & $\begin{array}{l}100.003 \\
\pm 0.822\end{array}$ & $\begin{array}{l}99.954 \\
\pm 1.314\end{array}$ & $\begin{array}{l}99.679 \\
\pm 1.211\end{array}$ & $\begin{array}{l}99.964 \\
\pm 1.068\end{array}$ & $\begin{array}{l}99.914 \\
\pm 0.947\end{array}$ & $\begin{array}{l}99.751 \\
\pm 1.271\end{array}$ & $\begin{array}{l}99.86 \\
\pm 1.206\end{array}$ \\
\hline RMSEP & 0.1903 & 0.0548 & 0.1038 & 0.0676 & 0.1485 & 0.0587 & 0.0887 & 0.0903 \\
\hline Predicted versus actual concentration plot & & & & & & & \\
\hline a-Slope & 0.9955 & 0.9922 & 1.0037 & 1.0054 & 0.9969 & 0.9932 & 1.010 & 1.0116 \\
\hline b-Intercept & 0.0769 & 0.0453 & -0.0253 & -0.0485 & 0.0409 & 0.0330 & -0.0685 & -0.0744 \\
\hline c-Correlation coefficient (r) & 0.9996 & 0.9999 & 0.9998 & 0.9998 & 0.9998 & 0.9999 & 0.9999 & 0.9996 \\
\hline
\end{tabular}

Table 6 shows statistical comparison of the results obtained by the proposed method and the official method, which is an HPLC method that uses $\mathrm{C}_{18}$ column and a mobile phase consisting of phosphate bufferacetonitrile in the ratio of 94:6 v/v [3] when applied to pure PC and DH. The calculated t and $\mathrm{F}$ values were smaller than the theoretical ones, indicating that there is no significant difference between the proposed method and the established method with respect to accuracy and precision.

Table 6.Statistical comparison of the results obtained by the proposed methods and the established method for determination of pure paracetamol (PC) and diphenhydramine hydrochloride (DH).

\begin{tabular}{|c|c|c|c|c|c|c|c|c|}
\hline \multirow{2}{*}{ Items } & \multicolumn{2}{|c|}{${ }^{2}$ DD method } & \multicolumn{2}{|l|}{ PLS } & \multicolumn{2}{|l|}{ PCR } & \multicolumn{2}{|c|}{$\begin{array}{l}\text { established } \\
\text { method }^{\mathrm{c}}\end{array}$} \\
\hline & PC & DH & PC & DH & PC & DH & PC & DH \\
\hline Mean & 100.720 & 100.130 & 100.047 & 100.003 & 99.964 & 99.914 & 100.11 & 99.96 \\
\hline SD & 0.493 & 0.618 & 1.357 & 0.822 & 1.068 & 0.947 & 0.868 & 0.743 \\
\hline $\mathbf{N}$ & 10 & 10 & 12 & 12 & 12 & 12 & 6 & 6 \\
\hline Variance & 0.243 & 0.382 & 1.841 & 0.676 & 1.141 & 0.897 & 0.753 & 0.552 \\
\hline $\begin{array}{l}\text { Student's } \\
\text { t-test }\end{array}$ & $\begin{array}{l}0.470 \\
(2.228)^{\mathrm{a}}\end{array}$ & $\begin{array}{l}0.703 \\
(2.228)^{\mathrm{a}}\end{array}$ & $\begin{array}{l}0.921 \\
(2.179)^{\mathrm{a}}\end{array}$ & $\begin{array}{l}0.922 \\
(2.179)^{\mathrm{a}}\end{array}$ & $\begin{array}{l}0.806 \\
(2.179)^{\mathrm{a}}\end{array}$ & $\begin{array}{l}0.901 \\
(2.179)^{\mathrm{a}}\end{array}$ & & \\
\hline F-value & $\begin{array}{l}3.099 \\
(3.217)^{b}\end{array}$ & $\begin{array}{l}1.445 \\
(3.217)^{b}\end{array}$ & $\begin{array}{l}2.445 \\
(2.996)^{b}\end{array}$ & $\begin{array}{l}1.225 \\
(2.996)^{b}\end{array}$ & $\begin{array}{l}1.515 \\
(2.996)^{b}\end{array}$ & $\begin{array}{l}1.625 \\
(2.996)^{b}\end{array}$ & & \\
\hline \multicolumn{9}{|c|}{$\begin{array}{l}{ }^{\mathrm{a}} \text { Figures in parentheses represent the corresponding tabulated values of } \mathrm{t} \text { at } \mathrm{P}=0.05 \text {. } \\
{ }^{\mathrm{b}} \text { Figures in parentheses represent the corresponding tabulated values of } \mathrm{F} \text { at } \mathrm{P}=0.05 \text {. } \\
\text { c } \mathrm{HPLC} \text { method, }{ }^{[3]} \text {. }\end{array}$} \\
\hline
\end{tabular}

Table 7 shows statistical comparison of the results obtained by the proposed method and the official method [3] when applied to PC and DH in Panadol night ${ }^{\circledR}$ tablets. The calculated $\mathrm{t}$ and $\mathrm{F}$ values were smaller than the theoretical ones, indicating that there is no significant difference between the proposed method and the established method with respect to accuracy and precision. 
Table 7.Statistical comparison of the results obtained by the proposed methods and the established method for determination of paracetamol (PC) and diphenhydramine hydrochloride (DH) in Panadol night ${ }^{\circledR}$ tablets(batch no. 124992).

\begin{tabular}{|c|c|c|c|c|c|c|c|c|}
\hline \multirow[t]{2}{*}{ Items } & \multicolumn{2}{|c|}{${ }^{2}$ DD method } & \multicolumn{2}{|l|}{ PLS } & \multicolumn{2}{|l|}{ PCR } & \multicolumn{2}{|c|}{$\begin{array}{l}\text { established } \\
\text { method }^{c}\end{array}$} \\
\hline & PC & DH & $\mathbf{P C}$ & DH & PC & DH & PC & DH \\
\hline Mean & 98.36 & 103.84 & 98.30 & 103.75 & 98.32 & 103.81 & 98.35 & 103.80 \\
\hline SD & 0.045 & 0.380 & 0.067 & 0.431 & 0.067 & 0.468 & 0.064 & 0.421 \\
\hline $\mathbf{N}$ & 6 & 6 & 6 & 6 & 6 & 6 & 6 & 6 \\
\hline Variance & 0.002 & 0.144 & 0.004 & 0.186 & 0.004 & 0.219 & 0.004 & 0.177 \\
\hline $\begin{array}{l}\text { Student's } \\
\text { t-test }\end{array}$ & $\begin{array}{l}0.92 \\
(2.23)^{\mathrm{a}}\end{array}$ & $\begin{array}{l}0.86 \\
(2.23)^{\mathrm{a}}\end{array}$ & $\begin{array}{l}0.20 \\
(2.23)^{\mathrm{a}}\end{array}$ & $\begin{array}{l}0.84 \\
(2.23)^{\mathrm{a}}\end{array}$ & $\begin{array}{l}0.44 \\
(2.23)^{\mathrm{a}}\end{array}$ & $\begin{array}{l}0.95 \\
(2.23)^{\mathrm{a}}\end{array}$ & & \\
\hline F-value & $\begin{array}{l}2.00 \\
(4.28)^{b}\end{array}$ & $\begin{array}{l}1.29 \\
(4.28)^{b}\end{array}$ & $\begin{array}{l}1.00 \\
(4.28)^{b}\end{array}$ & $\begin{array}{l}1.06 \\
(4.28)^{b}\end{array}$ & $\begin{array}{l}1.00 \\
(4.28)^{b}\end{array}$ & $\begin{array}{l}1.22 \\
(4.28)^{b}\end{array}$ & & \\
\hline
\end{tabular}

\section{Conclusion}

The present work provides new sensitive, accurate and selective analytical techniques for the determination of PC and DH in the presence of their degradates PAP and NOD in bulk powder or in pharmaceutical formulation. Application of the proposed method to the analysis of PC and DH in laboratoryprepared mixtures and pharmaceutical formulation shows that neither the degradation products nor the excipients interfere with the determination, indicating that the proposed methods could be applied as stabilityindicating methods for the determination of pure $\mathrm{PC}$ and $\mathrm{DH}$ and in the presence of the mentioned degradation products either in bulk powder or in pharmaceutical formulations.

\section{References}

[1] Martindale, the complete drug reference(The Extra Pharmacopoeia, 31st Edition Pharmaceutical press London, 2007).

[2] The Merk Index, 13th Edition(Merk Research Laboratories Division Of Merk and Co., Inc., Whitehouse Station, NJ, 607, 2001).

[3] The United States Pharmacopeia and National Formulary (The official Compendia of Standards, Asian Edition, USP 30-NF 25.The United States Pharmacopeial Conversion Inc., Rockvill, MD, 2007).

[4] C.Martínez-Algaba, JM.Bermúdez-Saldaña, RM.Villanueva-Camañas, S.Sagrado, MJ.Medina-Hernández, Analysis of pharmaceutical preparations containing antihistamine drugs by micellar liquid chromatography,J Pharm Biomed Anal,40,2006, 312-321.

[5] M. L.Qi, P.Wang, L.Zhou, Y.Sun, Simultaneous determination of four active components in a compound formulation by liquid chromatography,Chromatographia, 58, 2003, 183-186.

[6] H.Luo, L. J.Wang, J.Wang, Studies on quantitative determination of ingredients in Dextromethorphan Hydrobromide Diphenhydramine Hydrochloride Paracetamol Pseudoephedrine Hydrochloride dispersed tablets by HPLC,YaowuFenxi Zazhi,22,2002, 222-224.

[7] D.Ying, S. Ying, R. Yuqiu, R. Yulin, Artificial neural network for simultaneous determination of two components of compound paracetamol and diphenhydramine hydrochloride powder on NIR spectroscopy,AnalyticaChimicaActa, 528,2005, 55-61.

[8] C. G. Héctor, CO. Alejandro,Simultaneous multivariate spectrophotometric analysis of paracetamol and minor components (diphenhydramine or phenylpropanolamine) in tablet preparations,J Pharm Biomed Anal,20,1999, $255-261$.

[9] NW. Ali, HE. Zaazaa, M. Abdelkawy, MA. Magdy,Simultaneous Determination of Paracetamol and Diphenhydramine Hydrochloride in Presence of Paracetamol Degradation Product, Pharm Anal Acta, 2, 2011,140.

[10] R. Kramer,Chemometric Techniques for Quantitative Analysis (Marcel Dekker, Inc.,New York,1998). 